Srivastava, Rajendra. (2003) Applications of Belief Functions in Business Decisions: A Review. Information Systems Frontiers, 5 (4), 359-378. Publisher's Official Version: <http://www.som.buffalo.edu/isinterface/ISFrontiers/>.

Open Access Version: <http://kuscholarworks.ku.edu>.

[This document contains the author's accepted manuscript. For the publisher's version, see the link in the header of this document.]

\title{
Applications of Belief Functions in Business Decisions: A Review
}

\author{
By Rajendra P. Srivastava and Liping Liu \\ The University of Kansas, The University of Akron
}

\section{Paper citation:}

Srivastava, Rajendra. (2003) Applications of Belief Functions in Business Decisions: A Review. Information Systems Frontiers, 5 (4), 359-378.

\begin{abstract}
:
In this paper, we review recent applications of Dempster-Shafer theory (DST) of belief functions to auditing and business decision-making. We show how DST can better map uncertainties in the application domains than Bayesian theory of probabilities. We review the applications in auditing around three practical problems that challenge the effective application of DST, namely, hierarchical evidence, versatile evidence, and statistical evidence. We review the applications in other business decisions in two loose categories: judgment under ambiguity and business model combination. Finally, we show how the theory of linear belief functions, a new extension of DST, can provide an alternative solution to a wide range of business problems.
\end{abstract}




\title{
Applications of Belief Functions in Business Decisions: A Review
}

\author{
Rajendra P. Srivastava \\ Ernst \& Young Professor of Accounting and Director \\ Ernst \& Young Center for Auditing Research and Advanced Technology \\ Division of Accounting and Information System \\ School of Business, The University of Kansas \\ Lawrence, Kansas 66045 \\ Phone: (785) 864-7590, Fax: (785) 864-5328 \\ Email: rsrivastava@ku.edu
}

\section{Liping Liu}

Associate Professor of Management and Information Systems

University of Akron

College of Business Administration 351

Akron, $\mathrm{OH} 44325-4801$

Phone: (330) 972-5947, Fax: (330) 972-6588

Email: liu@acm.org 
Srivastava, Rajendra. (2003) Applications of Belief Functions in Business Decisions: A Review. Information Systems Frontiers, 5 (4), 359-378. Publisher's Official Version: <http://www.som.buffalo.edu/isinterface/ISFrontiers/>.

Open Access Version: <http://kuscholarworks.ku.edu>.

\title{
Applications of Belief Functions in Business Decisions: A Review
}

\begin{abstract}
In this paper, we review recent applications of Dempster-Shafer theory (DST) of belief functions to auditing and business decision-making. We show how DST can better map uncertainties in the application domains than Bayesian theory of probabilities. We review the applications in auditing around three practical problems that challenge the effective application of DST, namely, hierarchical evidence, versatile evidence, and statistical evidence. We review the applications in other business decisions in two loose categories: judgment under ambiguity and business model combination. Finally, we show how the theory of linear belief functions, a new extension of DST, can provide an alternative solution to a wide range of business problems.
\end{abstract}

\section{INTRODUCTION}

The notion of belief functions can be traced to its ancient root, the work of Jakob Bernoulli on pooling pure evidence. In modern language, an item of pure evidence proves a statement with a certain probability but has no opinions on its negation. Probabilities in accordance with pure evidence are non-additive. Bernoulli's idea of non-additive probabilities has now been well developed by Dempster $(1966,1967)$, Shafer (1976), and many others, under the name of DempsterShafer theory (DST) of belief functions. In recent years, there has been a significant surge in applications of belief functions to business decisions ranging from audit decisions and managing stock portfolios to forecasting demand for mobile satellite services (see, e.g., Srivastava and Mock 2002). One can attribute the reasons for this surge to (1) the ease with which belief functions map uncertainties present in the real world, (2) the theoretical developments in local computations for propagating belief functions in a network (see. e.g., Shenoy and Shafer 1986, 1990), and (3) availability of friendly software incorporating the local computations such as 'Auditor's Assistant' by Shafer et al. (1988), 'Pulcinella' by Saffiotti and Umkehrer (1991), and “ABEL’ by Anrig et al. (1997).

In this paper, we focus on the review of recent applications in auditing and other business decision problems and emphasize their techniques of mapping real-world uncertainties using belief functions. Our choice of the review scope answers a renewed call for more applications of 
Srivastava, Rajendra. (2003) Applications of Belief Functions in Business Decisions: A Review. Information Systems Frontiers, 5 (4), 359-378. Publisher's Official Version: <http://www.som.buffalo.edu/isinterface/ISFrontiers/>.

Open Access Version: <http://kuscholarworks.ku.edu>.

DST to real business and engineering problems (Dempster 2001). It also reflects our basic position that, when putting belief functions into practice, the most challenging task is how to encode evidence using the belief function formalism, e.g., focal elements and belief mass assignments (see Shafer 1976). We realize that our choice will inevitably exclude many related contributions from the review, notably the ones on the methods of embedding belief functions into the normative decision model (Jaffray 1989; Strat 1990; Yager 1989) and on the implementation of belief functions in decision support systems (Xu 1992; Liu and Shenoy 2002).

We organize this review using two threads. First, we review the applications in two broad application domains, namely, audit decisions and other business decisions. Second, within each domain, we review the existing studies by focusing on how they encode evidence and which features of DST they take advantage of. An outline of this paper is as follows. Section 2 shows how belief function can better represent uncertainties than probabilities in auditing and business decisions. Section 3 presents the audit process and how belief functions are applied to audit decisions including the work done in audit decisions under the risk of fraud. Section 4 discusses the other business applications of belief functions. Section 5 shows how the notion of linear belief functions, a recent extension to DST, is applied in auditing and other business decisions. Finally, Section 6 presents a summary and conclusion.

\section{MAPPING UNCERTAINTIES}

The essence of the belief function formalism is to encode evidence in terms of its evidential support for propositions involving uncertainty and to represent the degree of the support through the belief mass assignment (BMA) (Shafer 1976; Smets 1990a, 1990b, 1998). Let $\boldsymbol{X}$ be a set of finite discrete variables, $\Omega$ be its frame of discernment (Shafer 1976), and $A$ be a subset of $\Omega$. We interpret $A$ to be the statement that the true value of $\boldsymbol{X}$ is in $A$. We represent the degree of evidential support for $A$ by $m(A)$, which satisfies the following axioms, where $\phi$ is the empty set:

$$
0 \leq m(A) \leq 1, m(\phi)=0, \Sigma\{m(A) \mid A\}=1 .
$$

Semantically, $m(A)$ represents a portion of our total belief mass allocated to $A$ in accordance with a piece of evidence. It expresses the belief that one commits exactly to $A$. To obtain the total belief committed to $A$ including that to any subset of $A$, one may use a belief function $\operatorname{Bel}(A)$ and a plausibility function $\operatorname{Pl}(A)$ as follows: 
Srivastava, Rajendra. (2003) Applications of Belief Functions in Business Decisions: A Review. Information Systems Frontiers, 5 (4), 359-378. Publisher's Official Version: <http://www.som.buffalo.edu/isinterface/ISFrontiers/>.

Open Access Version: <http://kuscholarworks.ku.edu>.

$$
\operatorname{Bel}(A)=\sum_{B \subseteq A} m(B), P l(A)=\sum_{A \cap B \neq \phi} m(B) .
$$

Here, $\operatorname{Bel}(A)$ expresses the total belief that one commits to $A$. On the other hand, $\operatorname{Pl}(A)$ expresses the total belief that one does not commit to the negation of $A$ since $P l(A)=1-\operatorname{Bel}(\Omega-A)$.

A statement is called a focal element if there exists a piece of evidence in support of a positive BMA to it, i.e., $m(A)>0$. Note that, if there is lack of evidence justifying a more specific allocation, a portion of our total belief allocated to a focal element $A$ does not necessitate the allocation of any partial belief to its subsets. In other words, a positive $m(A)$ does not automatically imply a finer re-allocation of it into any subsets of $A$. This property of the belief mass assignments makes the notion of belief function distinct from that of probabilities. As a matter of fact, if all the focal elements are singletons, the belief function is reduced to a Bayesian probability function. Consequently, one may think of Bayesian theory of probabilities as a special case of DST (Shafer 1976).

A most important advantage of the belief function modeling is its ability to represent ignorance and partial ignorance. In the extreme case, if one is completely ignorant about variable $\boldsymbol{X}$, DST represents the ignorance by assigning the whole belief mass to $\Omega$, i.e., using a vacuous belief function. In contrast, Bayesian theory would represent it as a uniform distribution, which Shafter (1976) considers to mix lack of belief with disbelief. In essence, Bayesian theory does not allow one to withhold belief from a statement without according that belief to the negation of the statement.

To demonstrate the advantage of DST in representing partial ignorance, let us consider the classic example of non-additive probabilities (Hacking 1975). Suppose I find a scrap of newspaper predicting a blizzard $(b)$, which I regard as infallible. Also, suppose I am 75\% certain that the newspaper is today's. Then, I am $75 \%$ sure of a upcoming blizzard, i.e., $m(b)=0.75$. However, if the newspaper is not today's, anything can happen since the newspaper carries no information on future weather. Accordingly, we allocate the remaining belief mass $25 \%$ to both "blizzard" and "no blizzard" as a whole, i.e., $m(\{b, \sim b\})=0.25$. Note that, in this case, it is insensible to divide the belief mass 0.25 and assign partial beliefs to $b$ and $\sim b$ because there exists no evidence in support of such a re-allocation. Therefore, different from Bayesian theory, DST assigns no positive belief to $\sim b$. 
Srivastava, Rajendra. (2003) Applications of Belief Functions in Business Decisions: A Review. Information Systems Frontiers, 5 (4), 359-378. Publisher's Official Version: <http://www.som.buffalo.edu/isinterface/ISFrontiers/>.

Open Access Version: <http://kuscholarworks.ku.edu>.

Now let us consider an auditing example to illustrate how well belief functions map uncertainties faced in the real world. Suppose that the auditor is conducting an audit of the financial statements of a company and has gathered evidence to support that the management has integrity and honesty, and also recalls that there has been no errors or irregularities in the financial statements in prior years. This piece of information, in the auditor's judgment, provides a positive but a low level of support that the financial statements are fairly presented. Let us say, on a scale of 0 - 1 , this low level of support is 0.2 , i.e., $m(f)=0.2$, where $f$ represents the state that the financial statements are fairly presented. However, based on the management integrity, honesty, and prior experience, the auditor thinks that there is no evidence in support that the financial statements are materially misstated. That is, the support that the financial statements are materially misstated is zero, i.e., $m(\sim f)=0$, where $\sim f$ represents the negation of $f$. Therefore, the remaining belief mass 0.8 is best allocated to $f$ and $\sim f$ as a whole, i.e., $m(\{f, \sim f\})=0.8$. It is impossible to represent such an item of evidence in the probability framework, because by doing so, one would have to assign a positive portion of the belief mass to $\sim f$, i.e., $m(\sim f)>0$, which contradicts the fact that there is no evidence in support of $\sim f$.

Srivastava and Shafer (1992) and Akresh et al. (1988) argue that belief functions provide a more flexible and adaptable way to encode evidence from a variety of sources. One aspect of this flexibility is that the belief-function framework reduces to probability framework under a special condition (Shafer and Srivastava 1993). Moreover, there is empirical evidence suggesting that the belief-function framework is a better representation for uncertainties present in the real world than probabilities. Recently, Harrison et al. (2002, see also, Harrison 1999) conducted a study dealing with auditors' assessment of the strength of audit evidence and found that a statistically significant percentage of the auditors' responses could be modeled only using belief functions and not using probabilities (see also, Curley and Golden 1994).

\section{AUDIT DECISIONS USING BELIEF FUNCTIONS}

There have been several different audit approaches proposed in the auditing literature. Among them the most common ones include balance sheet approach, transaction approach, risk-based approach, and assertion based approach (Leslie et al. 1986). However, with the current understanding of the audit process, we believe there is just one approach, the evidential reasoning approach. According to Arens and Loebbecke (2000, p. 9), auditing is "the accumulation and 
Srivastava, Rajendra. (2003) Applications of Belief Functions in Business Decisions: A Review. Information Systems Frontiers, 5 (4), 359-378. Publisher's Official Version: <http://www.som.buffalo.edu/isinterface/ISFrontiers/>.

Open Access Version: <http://kuscholarworks.ku.edu>.

evaluation of evidence about information to determine and report on the degree of correspondence between the information and established criteria." We note three important steps in their definition. The first step, of course, is the accumulation of evidence. The second step is the evaluation of evidence to determine the degree of correspondence between the information and established criteria. The third step is to report or express an overall opinion on the degree of correspondence. In essence, the third step deals with the aggregation of all the evidence to form an opinion about whether the information of the entity is in accordance with the established criteria.

\section{Audit Evidence}

For the audit of financial statements, the information consists of the account balances reported on the financial statements and the established criteria are the Generally Accepted Accounting Principles (GAAP). In the USA, financial statements consist of a set of four statements ${ }^{1}$ such as balance sheet, income statement, statement of cash flow, and statement of retained earnings. Examples of accounts on the balance sheet are cash, accounts receivable, inventory, etc., and on the income statement are sales, cost of goods sold, expenses, etc. To form an opinion about whether they present fairly the financial position of the company in accordance with GAAP, the auditor collects evidence related to financial statements. Some items of evidence may directly relate to the financial statements as a whole, some may relate to the individual account balance, some may relate to the individual audit objective or management assertions of these accounts, and some may relate to the audit objectives of the transaction streams. Some of these items of evidence may be positive and some may even be negative.

The accounting profession assumes that financial statements are the representations of the management of the company being audited. Thus, when the management prepares financial statements they are making certain assertions about the information reported through financial statements. Statement on Auditing Standards No. 31 (AICPA 1980) classifies these management assertions into five categories: Existence or Occurrence, Completeness, Valuation or Allocation,

\footnotetext{
${ }^{1}$ A balance sheet represents a snap shot of the company's assets, liabilities, and owners' equity as of the date of the report. For example, if cash on the balance sheet is $\$ 200,000$, this amount represents that the company has that much cash available on the date of the report. Where as, an income statement represents the summary of economic activities during a given period, the period of the income statement. For example, $\$ 100,000$ revenue shown on the income statement represents that the company had $\$ 100,000$ of sales activity during the period considered on the income statement.
} 
Srivastava, Rajendra. (2003) Applications of Belief Functions in Business Decisions: A Review. Information Systems Frontiers, 5 (4), 359-378. Publisher's Official Version: <http://www.som.buffalo.edu/isinterface/ISFrontiers/>.

Open Access Version: <http://kuscholarworks.ku.edu>.

Rights and Obligation, Presentation and Disclosure. For example, 'Existence or Occurrence' means that the management is asserting that all the assets and obligations reported on the balance sheet do exist and all the sales, cost of goods sold, and expenses reported on the income statement have really occurred during the fiscal period. See Arens and Loebbecke (2000) for the definitions of other assertions.

In order to decide whether an account balance is fairly stated, the accounting profession uses the logic that if all the management assertions for an account are met then the account is fairly stated. This logic assumes that the account balance and all its management assertions are related through an “AND” relationship (see, e.g., Leslie et al. 1986, Arens and Loebbecke 2000). In other words, the account is fairly stated if and only if all the management assertions are met. Similarly, it has been a traditional assumption that a financial statement such as the balance sheet is related to all its accounts through an "and" relationship. That is, the balance sheet is fairly stated if and only if all the accounts on it are fairly stated.

In order to facilitate accumulation of evidence to determine whether each of the management assertions is met, the accounting profession has developed two sets of objectives. One set of objectives deals with the fair presentation of the accounts on the balance sheet such as cash, accounts receivable, etc. This set known as 'Balance-Related Audit Objectives'. The other set deals with the fair presentation of transaction streams such as sales, expenses, etc. This set is known as 'Transaction-Related Audit Objectives'. There are nine balance-related audit objectives: Existence, Completeness, Accuracy, Classification, Cutoff, Detail Tie-in, Realizable Value, Rights and Obligations, and Presentation and Disclosure (see Arens and Loebbecke 2000 for definitions). These objectives are closely related to the management assertions. For example, the objectives: Existence, Completeness, and Rights and obligation, respectively, correspond to the management assertions: Existence or Occurrence, Completeness, and Rights and Obligation. The audit objectives: Accuracy, Classification, Cutoff, Detail Tie-in, Realizable Value, relate to the Valuation and Allocation assertion because they all deal with the valuation of the account balance on the balance sheet. There are six transaction related audit objectives: Existence, Completeness, Accuracy, Classification, Timing, Posting and summarization (see Arens and Loebbecke 2000 for definitions).

The above conceptual framework suggests that the auditor has to collect evidence to make sure that each audit objective of each account is met and consequently each account is 
Srivastava, Rajendra. (2003) Applications of Belief Functions in Business Decisions: A Review. Information Systems Frontiers, 5 (4), 359-378. Publisher's Official Version: <http://www.som.buffalo.edu/isinterface/ISFrontiers/>.

Open Access Version: <http://kuscholarworks.ku.edu>.

fairly stated, leading to the fair presentation of the whole financial statements. Leslie et al. (1986), while discussing the assertion based approach to auditing, provided a way to explicitly consider the indirect evidence from the transaction streams to bear upon the balance sheet account through specific audit objectives (assertions). For example, we know that the ending balance of accounts receivable $(E)$ is equal to the beginning balance $(B)$ plus the sales $(S)$ for the period minus the cash receipts $(C)$ on the sales (assume that sales returns and cash discounts are insignificant). Therefore, in terms of specific assertions, especially for 'Existence' and 'Completeness', we get the following relationships:

$$
\begin{aligned}
& E(\text { Existence })=B(\text { Existence })+S(\text { Existence })-C \text { (Completeness }), \\
& E(\text { Completeness })=B(\text { Completeness })+S(\text { Completeness })-C(\text { Existence }) .
\end{aligned}
$$

The above relationships suggest that if the auditor wants to determine whether the 'Existence' assertion is met for ending balance of accounts receivable $(E)$, then he or she can look for items of evidence that directly bear on the 'Existence' assertion of $E$ such as confirmations of selected accounts from customers. At the same time, he or she can consider indirect evidence from sales 'Existence' and cash receipts 'Completeness' for the 'Existence' assertion of $E$. That is, if sales exist (not overstated) and cash receipts on credit sales are complete (not understated) then existence assertion of the accounts receivable balance is met. It is important to note that this detailed relationship between balance sheet accounts (e.g., cash, accounts receivable, inventory, etc.) and the transaction streams (e.g., cash receipts, cash disbursements, sales, purchases etc.) helps the auditor perform an efficient audit (Leslie et al. 1986). Recently, the American Institute of Certified Public Accountants (AICPA) has incorporated the above approach into Statement on Auditing Standards No. 55 (AICPA 1988b) and also auditing textbooks have started integrating this concept into the audit process (e.g., Arens and Loebbecke 2000).

\section{Audit Risk Model}

AICPA (1983), through Statement on Auditing Standards No. 47 (SAS 47), provides a guideline on how to integrate items of evidence based on inherent factors along with the evidence obtained from the accounting control systems and substantive audit procedures such as statistical tests. The SAS 47 audit risk model, in essence, expresses the overall audit risk (AR) that the financial statements are materially misstated, while the auditor has given a clean opinion, in terms of the product of three risks, IR, $\mathrm{CR}$, and $\mathrm{DR}$, i.e., $\mathrm{AR}=\mathrm{IR} \times \mathrm{CR} \times \mathrm{DR}$, where IR $=$ Inherent Risk, in- 
Srivastava, Rajendra. (2003) Applications of Belief Functions in Business Decisions: A Review. Information Systems Frontiers, 5 (4), 359-378. Publisher's Official Version: <http://www.som.buffalo.edu/isinterface/ISFrontiers/>.

Open Access Version: <http://kuscholarworks.ku.edu>.

herently the financial statements are materially misstated; $C R=$ Control Risk, internal accounting controls fails to detect and correct material misstatements, and DR = Detection Risk, the auditor's substantive test procedures fail to detect material misstatements. Conceptually, IR is the probability that there exist material errors. CR is the conditional probability that internal controls fail to detect and correct them given that such errors exist. DR is the conditional probability that the auditor's detection procedures fail to detect them given that such errors exist and that internal controls fail to detect and correct them. Consequently, AR represents the joint probability that there exist material errors while both test procedures and internal controls fail to detect them. Since the auditor's detection procedures consist of both analytical procedures and test of details, $\mathrm{DR}$ is often divided into two sub-components: $\mathrm{DR}=\mathrm{PR} \times \mathrm{TR}$. PR represents the risk that analytical procedures fail to detect material errors given that such errors exist and internal controls fail to detect and correct them. Similarly, TR is the risk that test of details fails to detect material errors given that such errors exist, internal controls have failed to detect and correct them, and the analytical procedures have also failed to detect them. For statistical test procedures, TR directly relates to Type II error.

The accounting profession implicitly assumes (Graham 1985a-1985e) that, when planning an audit of a specific account, say accounts receivable $(A / R)$, the auditor must first estimate an acceptable level of audit risk, say $\mathrm{AR}=0.05$, pertinent to a specific audit assertion for the account, next estimate the inherent risk, IR, and control risk, CR, pertinent to the specific audit assertion of the account. Based on the assessments of IR, and CR, the auditor plans the substantive test procedures in such a way that the detection risk, DR, yields the desired AR. In the extreme case, if the auditor assesses the inherent risk and control risk to be maximum (i.e., inherently the account could be materially misstated, and controls related to the audit assertion of interest are poor, i.e., $\mathrm{IR}=1$, and $\mathrm{CR}=1$ ), the planned level of detection risk, $\mathrm{DR}$, has to be the same as the audit risk. That is, the auditor has to depend only on the substantive audit procedures; no comfort is derived from the inherent factors or the control system. However, if the inherent factors, such as management integrity, trust, employees competence, economic environment of the company etc., suggest that IR can be assessed at a lower level than the maximum, say IR $=0.8$, and if the internal controls in the area of interest are reliable, i.e., the control risk is assessed below the maximum, say $\mathrm{CR}=0.6$, the detection risk, $\mathrm{DR}$, will be planned at 0.104 . 
Srivastava, Rajendra. (2003) Applications of Belief Functions in Business Decisions: A Review. Information Systems Frontiers, 5 (4), 359-378. Publisher's Official Version: <http://www.som.buffalo.edu/isinterface/ISFrontiers/>.

Open Access Version: <http://kuscholarworks.ku.edu>.

The audit risk model of SAS 47 is a conceptual model and has several limitations as discussed in the auditing literature (see, e.g., Boritz 1990, Boritz and Jensen 1985, Cushing and Loebbecke 1983, Graham 1985a-e, Kinney 1984, 1989, Lea, Adams, and Boykin 1992, Leslie 1984, Sennetti 1990). For example, we know that the structure of audit evidence, in general, forms a network of variables, variables being the accounts on the financial statements, audit objectives of the accounts and transaction streams, and the financial statements themselves. The SAS 47 model does not incorporate this network structure of the evidence (Srivastava et al. 1996). For another example, the model is interpreted as a probability model, but the way it recommends the assessment of uncertainties makes it a plausibility model in belief functions. As discussed by Srivastava and Shafer (1992), the values of IR, for example, when interpreted in probability terms lead to confusing interpretations:

... the auditor may believe, on the basis of inherent factors, that the account is fairly stated and yet be unwilling to rely on these factors past a certain point. In this case, the auditor may, as SAS No. 47 suggests, assign a value less than the maximum, say 70 percent, to inherent risk. If interpreted in probability terms, this number says that the inherent factors give a 30 percent chance that the account is not materially misstated and a 70 percent chance that it is materially misstated. This suggests that the evidence is negative, contrary to the auditor's intuition. The probability interpretation is even more confusing if the auditor sets the inherent risk at 50 percent. What does this mean? Does it mean that the auditor is completely ignorant about the state of the account, or does it mean there is more evidence that the account is not being materially misstated than when only 30 percent assurance was assumed?

\section{Evidential Reasoning with Hierarchical Evidence}

To overcome the limitations of the audit risk model, Srivastava and Shafer (1992) argue that there exists evidence at the audit objective level, at the account level, and also at the financial statement level. For examples, inherent factors related to the management integrity are examples of evidence at the financial statement level; the value of inventory using sampling technique is an example of evidence that pertains to a specific audit objective 'valuation'; the reasonableness of the account balance, say accounts receivables, concluded through analytical procedures, is an example of evidence at the account level.

Accordingly, Srivastava and Shafer (1992) derive analytical expressions of the audit risk at the three levels: the financial statement level, account level, and the audit objective level, with 
Srivastava, Rajendra. (2003) Applications of Belief Functions in Business Decisions: A Review. Information Systems Frontiers, 5 (4), 359-378. Publisher's Official Version: <http://www.som.buffalo.edu/isinterface/ISFrontiers/>.

Open Access Version: <http://kuscholarworks.ku.edu>.

the assumption that all the items of evidence obtained in the audit process are positive. In fact, in the planning stage, one would expect such evidence. They argue, in general, that evidence from inherent factors and analytical procedures would be present at all levels, the financial statement level, the account level, and the audit objective level. Also, they argue that the accounting systems and the relevant controls, and auditor's test of details for account balances would support at the audit objective level only. Therefore, there are four types of evidence at the objective level: Inherent factors (IO), accounting systems and controls (CO), analytical procedures (PO), and test of details performed by the auditor (TO). There are two items of evidence at the financial statement level and the account level: IO and PO.

By assuming no fraudulence ${ }^{2}$, the balance sheet is fairly presented when each account on the balance is fairly stated. Also, each account is fairly stated when all the audit objectives of the account are met. Logically all the audit objectives of an account are related through an "AND" node to the account and all the balance sheet accounts are related to the balance sheet as a whole through an "AND” node as shown in Figure 1 (Srivastava and Shafer 1992).

To encode hierarchical evidence into belief functions in Figure 1, Srivastava and Shafer (1992) interpret the risks as the plausibility that the corresponding variables are not met. For example, assume that the four items of evidence at the objective level are positive, and let ao denote the proposition that Objective $\mathrm{O}$ of account $\mathrm{A}$ is met and ao denote its negation. Then, $P l_{I O}(\sim \mathrm{ao})=\mathrm{IR}, P l_{C O}(\sim \mathrm{ao})=\mathrm{CR}, P l_{P O}(\sim \mathrm{ao})=\mathrm{PR}$, and $P l_{T O}(\sim \mathrm{ao})=\mathrm{TR}$. Accordingly, in terms of m-values, we have $m_{I O}(\mathrm{ao})=1-\mathrm{IR}, m_{I O}(\{\mathrm{ao}, \sim \mathrm{ao}\})=\mathrm{IR}, m_{I O}(\sim \mathrm{ao})=0 ; m_{C O}(\mathrm{ao})=1-\mathrm{CR}$, $m_{C O}(\{\mathrm{ao}, \sim \mathrm{ao}\})=\mathrm{CR}, m_{C O}(\sim \mathrm{ao})=0 ; m_{P O}(\mathrm{ao})=1-\mathrm{PR}, m_{P O}(\{\mathrm{ao}, \sim \mathrm{ao}\})=\mathrm{PR}, m_{P O}(\sim \mathrm{ao})=0 ;$ $m_{T O}(\mathrm{ao})=1-\mathrm{TR}, m_{T O}(\{\mathrm{ao}, \sim \mathrm{ao}\})=\mathrm{TR}, m_{T O}(\sim \mathrm{ao})=0$. Consequently, the plausibility that the account objective is not met will be $P l(\sim$ ao $)=\mathrm{AR}=\mathrm{IR} \times \mathrm{PR} \times \mathrm{CR} \times \mathrm{TR}$ (Srivastava and Shafer 1992, Eq. 16). The total belief that the objective is met, will be expressed as: $\operatorname{Bel}($ ao $)=1-\operatorname{IR} \times$ $\mathrm{PR} \times \mathrm{CR} \times \mathrm{TR}$.

\footnotetext{
${ }^{2}$ In the current discussion, it is assumed that the auditor is concerned about only the material 'errors' and 'irregularities' as defined in SAS 53 (AICPA 1988a). However, we will discuss later a different approach (see, e.g., Dutta et al. 1998, and Turner et al. 2002) where the financial statements are considered to be fairly stated under the condition that there is no fraud and no material errors and irregularities as suggested by SAS 82 (AICPA 1997).
} 


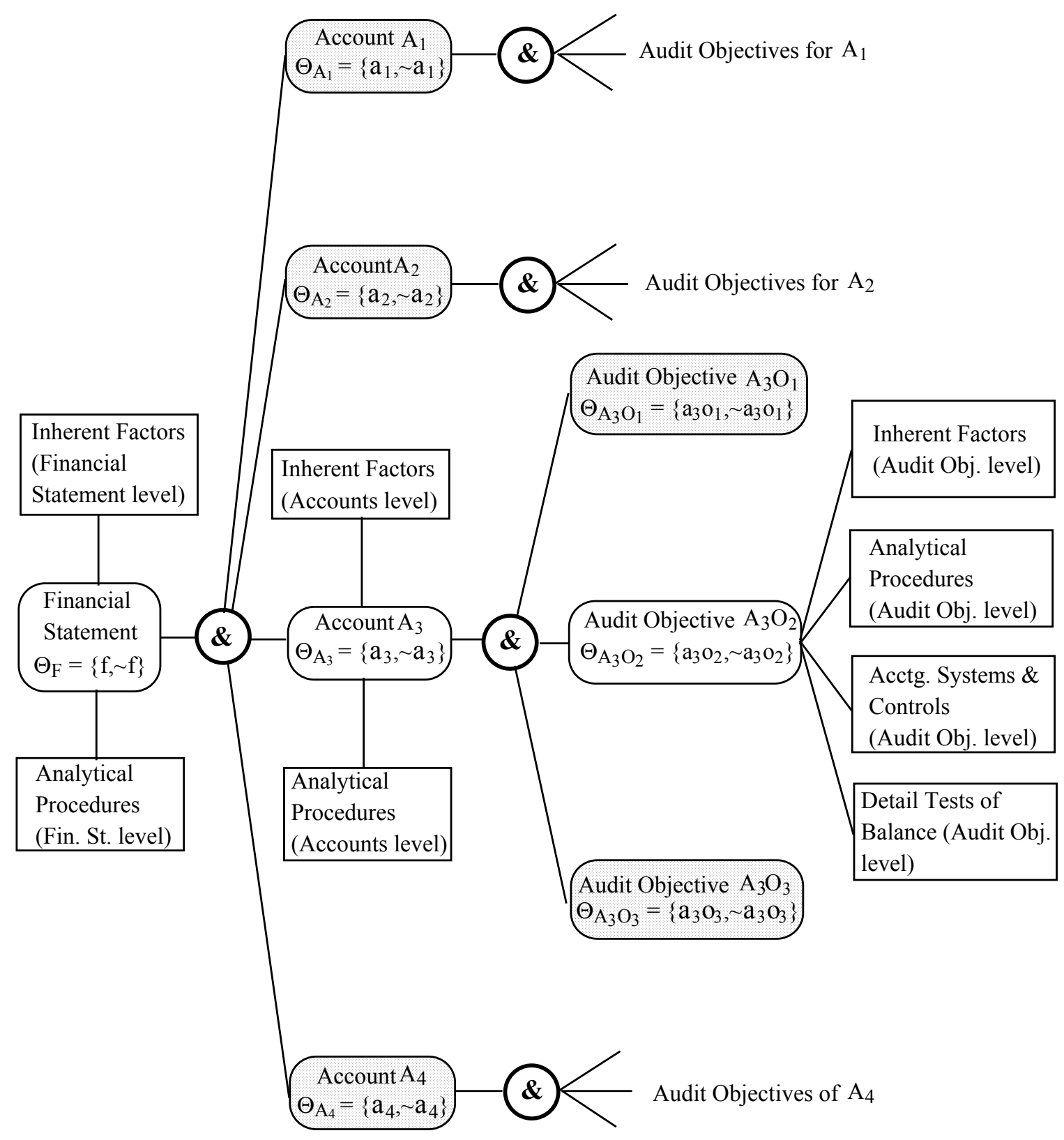

Figure 1. An Evidential Network Assuming No Fraud

Note: The figure is taken from Srivastava and Shafer (1992). A rounded rectangle represents a variable (variables being the financial statements as a whole, various accounts, and the related audit objectives). A rectangle represents an item of audit evidence. The evidence is connected to a variable that it directly supports. A circle with ' $\&$ ' implies that the variable on the left is true if and only if the variables on the right of the circle are true.

The plausibility interpretation of audit risk is intuitive in the auditing context. It measures how risky the auditor feels if he or she had to stop collecting further evidence. It provides a non- 
Srivastava, Rajendra. (2003) Applications of Belief Functions in Business Decisions: A Review. Information Systems Frontiers, 5 (4), 359-378. Publisher's Official Version: <http://www.som.buffalo.edu/isinterface/ISFrontiers/>.

Open Access Version: <http://kuscholarworks.ku.edu>.

frequentist interpretation of the auditing concept of risk. Suppose the auditor had obtained a total belief of 0.95 that the overall financial statements are fairly presented and there is no evidence that they are materially misstated. The plausibility in this case that the financial statements are materially misstated is 0.05 , which represents the audit risk according to the belief function interpretation. Now suppose the auditor issues an unqualified opinion given that he or she has obtained a 95 percent of belief that the financial statements are fairly stated. The risk the auditor is taking that the financial statements may contain material errors is 0.05 , although there is no evidence that the financial statements are materially misstated. In fact, this is what the auditor may have thought when he or she gave his opinion on the financial statements.

\section{Evidential Reasoning with Versatile Evidence}

Some audit evidence pertains to only one variable but some pertains to more than one variable. For example, confirmations of accounts receivable from customers pertain to two audit objectives: 'existence' and 'valuation'. Consequently, the evidential diagram becomes a network (Mock et al. 1998, Srivastava et al. 1996, Srivastava and Lu 2002). In contrast, Srivastava and Shafer (1992) assumed a tree type structure in order to develop the analytical audit risk model based on plausibility values at the three levels of the financial statement.

If we can encode all the audit evidence in terms of belief functions, combining various items of evidence, whether in a tree or network structure, becomes essentially a problem of propagating beliefs in a network (see, e.g., Shenoy and Shafer 1986, 1990, Srivastava 1995a, 1995b). Srivastava, Shenoy, and Shafer (1995) have developed propositions that make it easier to aggregate audit evidence in an "and" tree. However, a challenge with a network is how we can encode versatile evidence that pertains to more than one variable. As mentioned earlier, confirmations of accounts receivable may provide support to both 'Existence' and 'Valuation' objectives of accounts receivable but at different levels. The initial judgment can be expressed in terms of m-values on individual objectives. However, since the evidence is coming from a single source, these m-values need to be expressed in terms of the variables on the joint space in order to (1) combine all the evidence in the network, and (2) preserve the interdependencies among the evidence. In general, the conversion process can become quite complex depending on the number of variables involved and the nature of the individual support whether it is positive or negative (see, e.g., Dubois and Prade 1986, 1987, 1992, and 1994). Srivastava and Cogger developed 
Srivastava, Rajendra. (2003) Applications of Belief Functions in Business Decisions: A Review. Information Systems Frontiers, 5 (4), 359-378. Publisher's Official Version: <http://www.som.buffalo.edu/isinterface/ISFrontiers/>.

Open Access Version: <http://kuscholarworks.ku.edu>.

a heuristic approach to convert such individual beliefs into beliefs on the joint space (see, e.g., Srivastava 1997b). Srivastava and his co-researchers use this approach for evidential reasoning in auditing along with a computer program 'Auditor's Assistant' developed by Shafer, Shenoy and Srivastava (1988).

Let us consider a simple illustration of the above issue where one item of evidence supports multiple objectives at different levels. Suppose the auditor has mailed 100 confirmations to the client's customers asking them to respond whether they owe the stated amount to the company. Consider that the auditor has received all the confirmations stating that they owed the company but with disputes in some cases regarding the amount owed. Based on this evidence, the auditor thinks he or she has, say, 0.8 level of support that 'Existence' objective is met, and a lower level of support, say, 0.6 , that the 'Valuation' objective is met. In terms of m-values, one can represent this evidence as:

$$
m(e)=0.8, m(\sim e)=0, m(\{e, \sim e\})=0.2, m(v)=0.6, m(\sim v)=0, m(\{v, \sim v\})=0.4,
$$

where ' $e$ ' represents that 'Existence' objective is met, ' $v$ ' represents that 'Valuation' objective is met, and ' $\sim e$ ', and ' $\sim v$ ' represent the negation of ' $e$ ' and ' $v$ ', respectively. However, since the above belief masses originate from a single source, one needs to convert the above m-values into $\mathrm{m}$-values on the joint space of the variables. Using the Srivastava and Cogger (Srivastava 1997b) approach one can express them as:

$$
m(e v)=0.6, m(\{e v, e \sim v\})=0.2, m(\{e v, e \sim v, \sim e v, \sim e \sim v\})=0.2 .
$$

where $e v, e \sim v, \sim e v, \sim e \sim v$ are respectively the joint events of $e$ and $v, e$ and $\sim v, \sim e$ and $v$, and $\sim e$ and $\sim v$. As one can easily verify, the marginal values of the above function yield the desired individual m-values.

\section{Integrating Statistical and Non-Statistical Evidence}

We know that the auditor collects both statistical and non-statistical items of evidence on every engagement. An example of statistical evidence is the procedure to determine the value of inventory using a statistical sampling technique (see, e.g., Arens and Loebbecke 2000, and Guy et al. 2002). At the moment, an auditor often uses an intuitive approach to combine such items of evidence. However, the problem is that the auditor is not able to take full advantage of the strength of evidence that may be non-statistical in nature to save on the extent of work done for statistical tests. Srivastava and Shafer (1994) show how one can convert statistical evidence, es- 
Srivastava, Rajendra. (2003) Applications of Belief Functions in Business Decisions: A Review. Information Systems Frontiers, 5 (4), 359-378. Publisher's Official Version: <http://www.som.buffalo.edu/isinterface/ISFrontiers/>.

Open Access Version: <http://kuscholarworks.ku.edu>.

pecially, in a variable sampling technique, to evidence in belief functions. Gillett and Srivastava (2000) extend the work of Srivastava and Shafer (1994) to attribute sampling. Auditors use attribute sampling in testing effectiveness of internal controls in accounting information systems.

Jung and Fink (2002) compare the effectiveness and efficiency of audit procedures using three different approaches. They perform simulation study to determine the audit risk in complex situations and contend that the "belief based audit is always more efficient than a simple one and can be less efficient than the traditional approach." They also mention that the belief-based approach is the most effective among the three models used.

Dollar Unit Sampling or Monetary Unit Sampling (see, e.g., Arens and Loebbecke 2000) is a commonly used statistical test by auditors for predicting the account balances. Gillett (1996, 2000) provides how statistical evidence obtained through Dollar Unit Sampling can be converted into belief functions.

\section{Audit Decision under the Risk of Fraud}

Dutta et al. (1998) developed a simple analytical audit-planning model under the belief-function framework by considering explicitly the risk of fraud. They argue that the financial statements are fairly presented if and only if there is no fraud and no errors and irregularities. In fact, this reasoning has been incorporated in auditing through the Statement on Auditing Standards No. 82 (AICPA 1997a). Since there are several distinct procedures for detecting fraud, the above reasoning leads to two separate branches in the evidential network, one, dealing with 'errors and irregularities' and the other dealing with 'fraud'.

Recently, Turner et al. (2002) have developed a rigorous framework (see Figure 2) to assist audit planning and evaluation by explicitly considering the possibility of fraud. The model is based on an evidential network that has two major sub-networks as mentioned above: one to capture evidence for a conventional financial statement audit and the other to capture the evidence related to SAS No. 82 fraud risk assessment approaches. In essence, they address the following four research questions. First, what are the structures of evidential models for pre- and post-SAS audits? Second, what is the impact of positive and mixed (both positive and negative) evidence regarding management integrity on fraud risk and audit risk? Third, what is the impact of positive evidence regarding management integrity on fraud risk and audit risk when red flags are pre- 
Srivastava, Rajendra. (2003) Applications of Belief Functions in Business Decisions: A Review. Information Systems Frontiers, 5 (4), 359-378. Publisher's Official Version: <http://www.som.buffalo.edu/isinterface/ISFrontiers/>.

Open Access Version: <http://kuscholarworks.ku.edu>.

sent? Fourth, what is the impact of positive evidence regarding management integrity on fraud risk and audit risk if inappropriate forensic procedures are performed?

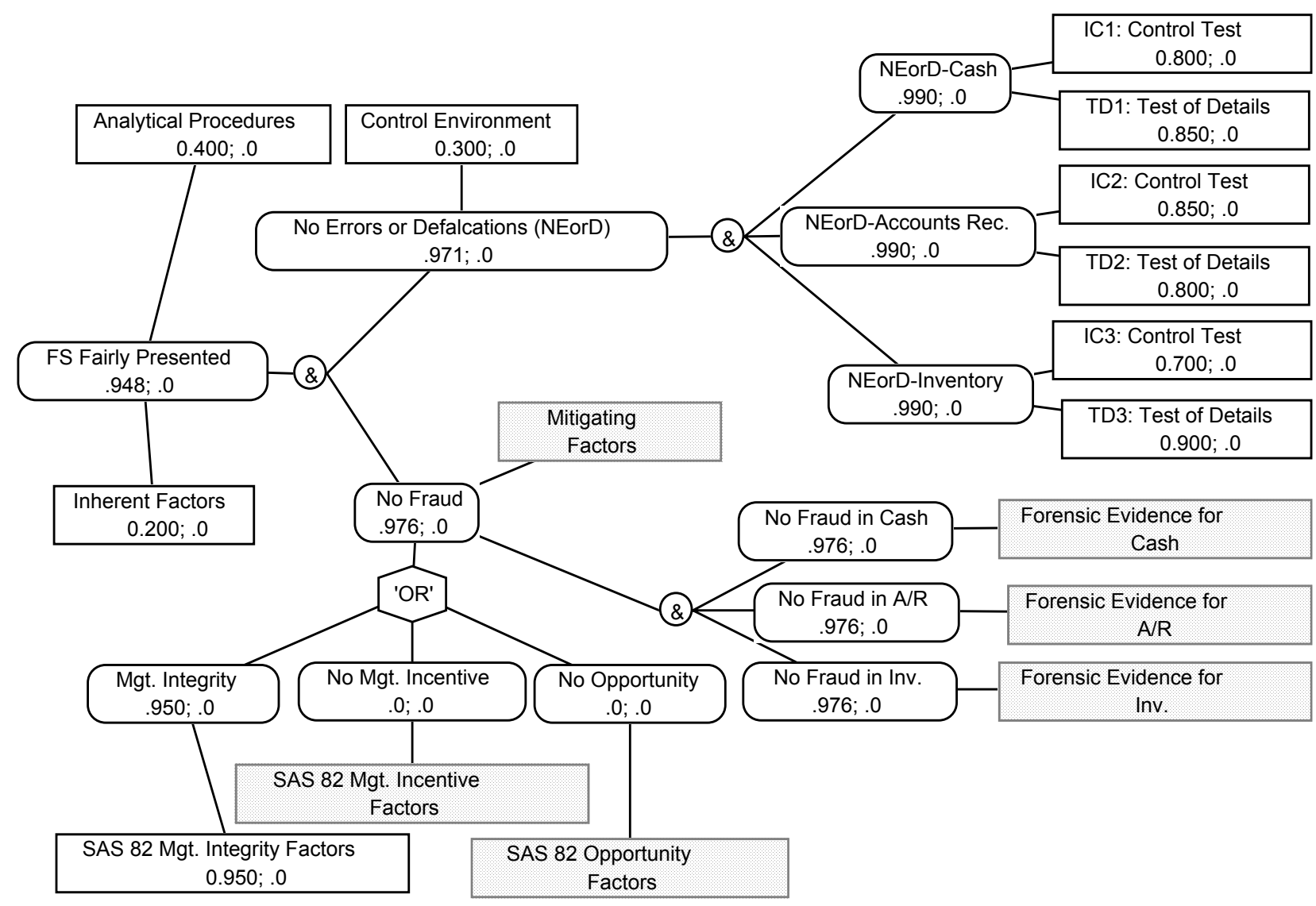

Figure 2. Generic Evidential Network

Note: This figure is taken from Turner, Mock, and Srivastava (2002). Case 1-Before SAS 82 the auditor has full confidence in the client that there is no fraud. The oval shaped boxes represent assertions and sub-assertions and the rectangular boxes represent items of evidence linked to the corresponding variables they pertain to. The first and second numbers in these boxes, respectively, represent the level of support in favor of and against the corresponding assertion or sub-assertion.

The fraud-risk factors used in Turner et al. (2002) were identified from actual audit engagements and information on the audit team's decisions concerning audit procedures that were modified to address the identified fraud risk factors (Mock and Turner 2002). In their model they consider that the fraud would occur if and only if the management lacks integrity and has incentive, such as bonus tied to earnings, and there is opportunity to commit fraud. They show that, prior to SAS No. 82, the auditing profession was implicitly assuming a very high level of management integrity and hence no risk of fraud. Also, they show that, when there is no question re- 
Srivastava, Rajendra. (2003) Applications of Belief Functions in Business Decisions: A Review. Information Systems Frontiers, 5 (4), 359-378. Publisher's Official Version: <http://www.som.buffalo.edu/isinterface/ISFrontiers/>.

Open Access Version: <http://kuscholarworks.ku.edu>.

garding the integrity of management, the existence of management incentives and the opportunity to commit fraud have little effect either on fraud risk or audit risk. However, if the auditor questions management integrity to some degree, management incentive and opportunity substantially increase both fraud risk and audit risk. In addition, they show that when there is both management incentive and opportunity in conjunction with a question as to the integrity of management, adding forensic procedures is the only viable option to reduce fraud risk and audit risk. It is important to note, as they point out, when there is both management incentive and opportunity in conjunction with a question as to the integrity of management, simply modifying or extending normal audit procedures without adding appropriate forensic procedures does little to reduce either fraud risk or audit risk.

\section{OTHER BUSINESS DECISIONS USING BELIEF FUNCTIONS}

In addition to audit decisions, there have been many applications of belief functions in other business decisions. One category of such applications deals with how managers make judgment and decisions when facing ambiguity. As in audit decisions, these applications are dictated by the representation of ignorance and partial ignorance using belief functions. However, there are some other applications that take advantage of Dempster's rule. We will review this second category of applications under a loose theme of business model combination.

\section{Judgment under Ambiguity}

Ellsberg (1961) offers a classic example of problems of decision-making under ambiguity. Suppose an urn contains 30 red balls and 60 others that are black or yellow in unknown proportion. One ball is chosen at random. Four acts are envisioned:

Act 1: win $\$ 1000$ if red is chosen and $\$ 0$ otherwise;

Act 2: win $\$ 1000$ if black is chosen and $\$ 0$ otherwise;

Act 3: win $\$ 1000$ if red or yellow is chosen and $\$ 0$ otherwise;

Act 4: win $\$ 1000$ if black or yellow is chosen and $\$ 0$ otherwise.

According to Ellsberg (1961), many people prefer Act 1 to Act 2 and Act 4 to Act 3. If we represent the ambiguity using probabilities, according to the subjective expected utility theory of Savage (1954), the choice of majority implies the following inequalities: 
Srivastava, Rajendra. (2003) Applications of Belief Functions in Business Decisions: A Review. Information Systems Frontiers, 5 (4), 359-378. Publisher's Official Version: <http://www.som.buffalo.edu/isinterface/ISFrontiers/>.

Open Access Version: <http://kuscholarworks.ku.edu>.

$$
\rho(r) V(1000)>\rho(b) \mathrm{V}(1000),[\rho(r)+\rho(y)] V(1000)<[\rho(b)+\rho(y)] V(1000),
$$

where $\rho(r), \rho(b)$, and $\rho(y)$ are the respective the probabilities of drawing red, black, and yellow colors, and $V(x)$ is the utility of payoff $x$ with $V(0)=0$. Note that, the above two inequalities are conflicting with each other because they can be respectively reduced to $\rho(r)>\rho(b)$ and $\rho(r)<$ $\rho(b)$. This conflict is now often referred to as the Ellsberg paradox.

In the Ellsberg's example, the choice of majority is reasonable in the sense that people are ambiguity averse. In the first comparison, a third of balls are red while the proportion of black ones is unspecified. In the second comparison, two-thirds of the balls are black and yellow while the proportion of red and yellow balls is unknown. In other words, there is ambiguity for event "black" and so for the outcome of Act 2 in the first comparison. Similarly, there is ambiguity for event "red or yellow" and so for the outcome of Act 3 when comparing Act 3 and Act 4. The obvious force of ambiguity aversion drives the choice of majority to be the one we observed.

There have been many resolutions proposed to explain the Ellsberg paradox. For example, Liu (1995a) argues that the expectation formulism lacks plausible semantics when it applies to a one-shot gamble. An expected utility was initially interpreted by Bernoulli as a measure of one's long-run average in multiple plays of a gamble. These semantics are adequate when uncertainty is represented by empirical frequencies, and the same gamble is repeated. However, applying the expected utility principle to a one-shot play of a gamble is counterintuitive (see also Hogarth and Einhorn 1990, Liu and Shenoy 1995b). Churchill Eisenhart illustrates this predicament nicely (see Hacking 1975). A Pacific naval base has a machine selling Coca-Cola at 5 cents a bottle. The price of Coke goes up to 6 cents. The machine takes only nickels. If at random one in every six bottles in the machine is empty, then the machine is undoubtedly fair. Such a mechanical vendor may be fine for the regular patrons but a casual visitor who has to pay a dime before he or she gets a drink is not likely to think the game fair even if he or she is warned beforehand.

The Ellsberg paradox raised a fundamental issue on whether uncertainties can be represented as probabilities. The foundation of the Bayesian theory (Savage 1954) builds on the affirmative answer to the question. However, the proponents of DST think otherwise. For example, many have suggested representing ambiguity using belief functions. Accordingly, Jaffray (1989, 1994), Strat (1990, 1994), and Yager (1989) have proposed to extend the subjective expected 
Srivastava, Rajendra. (2003) Applications of Belief Functions in Business Decisions: A Review. Information Systems Frontiers, 5 (4), 359-378. Publisher's Official Version: <http://www.som.buffalo.edu/isinterface/ISFrontiers/>.

Open Access Version: <http://kuscholarworks.ku.edu>.

utility theory to embed the belief function representation. In a study related to audit decisionmaking, Srivastava (1996) applies belief functions to understand how auditors make value judgments under ambiguity. Later, based on the model developed by Strat (1990, 1994), Srivastava (1997a) further explores decision-making behavior under ambiguity. He argues that the Ellsberg paradox is due to the difficulty in modeling ambiguity as probabilities. More interestingly, he notes that the belief-function approach models human decision behavior and value judgment more naturally than the traditional probabilistic approach. Srivastava and Mock (2000) discuss, in general, the relevance of belief functions in behavioral research in auditing.

Along the same line of inquiries as in Jaffray $(1989,1994)$, Strat $(1990,1994)$, and Yager (1989), Liu (1995a) suggests that, besides risk aversion, additional parameter(s) such as ambiguity aversion might be needed to explain one's attitudes to ambiguity. This is evidenced in some existing resolutions to the Ellsberg paradox. For example, Strat (1994) and Jaffray (1994) introduce a single parameter, interpreted as a pessimism index, to characterize one's attitude to ambiguity. Engemann et al. (1996) introduce multiple uncertainty parameters that are determined by setting up an appropriate degree of optimism $(\alpha)$ and maximizing their dispersion. When $\alpha=$ 0.5 , their model reduces to the subjective expected utility function. When $\alpha=1.0$, their model is the same as the Maximax model. When $\alpha=0$, it is the same as the Maximin model. The variational model of Fishburn (1993), although not using belief functions, adds a real parameter $\tau$, referred to as the coefficient of aversion to variability, to the subjective expected utility function. It reduces to the expected theory when $\tau$ is zero.

Turner (1994) has examined, in a quasi-experimental setting, three models that are descriptive of the audit judgment process: the Audit risk model, the Dempster-Shafer Belief Function Model, and the Hogarth and Einhorn Belief Adjustment Model (1992). Dusenbury et al. (1996) have performed empirical studies to compare the audit risk model of SAS 47 with two other models: the firm-based model, and a belief-based model. Krishnamoorthy et al. (1999) have used belief functions to analyze auditors' behavior in aggregating items of evidence to determine the likelihood of material misstatements in the valuation of inventory. Extending the research on audit risk, Monroe and Ng (2002) conduct an experiment where auditors are asked to make judgment about audit risk using their intuition and compare this with the value generated by various models. Interestingly, their findings indicate that there is no statistical difference between the auditor's intuitive assessments and the values generated by the belief function model. 
Srivastava, Rajendra. (2003) Applications of Belief Functions in Business Decisions: A Review. Information Systems Frontiers, 5 (4), 359-378. Publisher's Official Version: <http://www.som.buffalo.edu/isinterface/ISFrontiers/>.

Open Access Version: <http://kuscholarworks.ku.edu>.

Harrison (1999) conducted an experiment where he asked the auditor subjects to make judgment about whether the evidence is positive or negative pertaining to a specific audit objective and the level of support provided to various audit objectives without contaminating their thought process whether they express their judgment in terms of probabilities or belief functions. It is interesting to note that $80 \%$ of the responses were modeled only through belief functions.

Dutta and Srivastava (1999) have used belief functions to explain the auditor's behavior in aggregating evidence under the following conditions: (1) Sequential processing of evidence with all the items of evidence being positive. (2) Sequential processing of evidence with all the items of evidence being negative. (3) Sequential processing of mixed items of evidence starting with a positive item of evidence. (4) Sequential processing of mixed items of evidence starting with a negative item of evidence. (5) Simultaneously processing mixed items of evidence.

\section{Business Model Combination}

Many applications of DST deal with how to combine business data and models from multiple sources. Such applications include business forecasting, portfolio management, information quality assessment, etc. Unlike the applications in decision-making under ambiguity, these applications typically utilize the other advantages of the belief function modeling such as the combination of independent evidence by Dempster's rule and the representation of complex uncertainty by graphical models.

The AICPA and Canadian Institute of Chartered Accountants jointly published the criteria and principles to provide WebTrust services for creating trust in consumers' minds to conduct business through the Internet (AICPA 1997b, 1997c). Based on those criteria and principles, Srivastava and Mock (1999-2000) propose an evidential network for providing assurance on WebTrust services using belief functions. Sun et al. (2001) use a real case of a WebTrust service and determine the structure of the evidential network in the case. They have performed a sensitivity analysis to determine the relative importance of the evidence at various levels of the network and also investigated the impact of 'weighted average' relationship among the WebTrust sub-objectives and the main objective instead of 'and' relationship on the overall assurance or belief that the main objective is met. It is important to note that the 'weighted-average' relationship appears to map the auditor's judgment better than the 'and' relationship. 
Srivastava, Rajendra. (2003) Applications of Belief Functions in Business Decisions: A Review. Information Systems Frontiers, 5 (4), 359-378. Publisher's Official Version: <http://www.som.buffalo.edu/isinterface/ISFrontiers/>.

Open Access Version: <http://kuscholarworks.ku.edu>.

Similarly, Bovee et al. (2002) propose an evidential network for determining the quality of information. They identify the main attributes that determine the information quality. They argue that logically, similar to audit objectives, the information quality is high if and only if all the attributes are true. In other words, all the attributes are related to the main objective, the information quality being high, through an "and" relationship. Other relationships such as 'weighted average' with equal weights and varying weights are being investigated.

Srivastava and Datta (2002) apply the belief functions approach to the evaluation of mergers and acquisitions candidates. They also develop an evidential network for the decision and use belief functions to represent uncertainty in the evidence and use Dempster's rule of combination to determine the overall belief whether the target company is a good candidate of merger and/or acquisition.

McBurney and Parsons (2002) apply the belief-function framework to forecast demand for mobile satellite services. They find that belief functions provide a means of representing and combining varied beliefs for forecasting demand, which is more expressive than traditional point probability estimates. In a similar application, Bryson (2002) applies Dempster's rule to combine subjective probability judgments from a group of experts. He presents an integrated structured, non-invasive action learning knowledge elicitation process for eliciting from a group of experts, the subjective probabilities that are required by some DST-based expert systems. This process accommodates the expert's uncertainty, identifies inconsistencies in the expert's opinion, takes advantage of the potential benefits of group work while mitigating against the negative effects, and addresses the issues of consensus assessment and consensus building.

Shenoy and Shenoy (2002) demonstrate how the theory of belief functions can be used to model financial portfolios. In particular, they show how to model portfolio changes as new information becomes available about different factors that influence individual stocks or a portfolio. Finally, Lien (2002) provides an application of belief functions in economics. He discusses the relationship between Knightian uncertainty and belief functions and provides an illustration of a futures hedging decision under Knightian uncertainty.

\section{APPLICATIONS OF LINEAR BELIEF FUNCTIONS}

The notion of linear (or normal) belief functions (LBF) extends DST to the case when variables of interest are continuous. As we introduced before, a belief function in general is defined by a 
Srivastava, Rajendra. (2003) Applications of Belief Functions in Business Decisions: A Review. Information Systems Frontiers, 5 (4), 359-378. Publisher's Official Version: <http://www.som.buffalo.edu/isinterface/ISFrontiers/>.

Open Access Version: <http://kuscholarworks.ku.edu>.

BMA over a class of focal elements, which may have nonempty intersections. An LBF is a special type of belief functions in the sense that its focal elements are exclusive, parallel subhyperplanes over a hyperplane and its BMA is a normal distribution across the sub-hyperplanes. An LBF intends to represent our belief regarding the location of the true value as follows: We are certain that the truth is on a so-called certainty hyperplane but we do not know its exact location; along some dimensions of the certainty hyperplane, we believe the true value could be anywhere from $-\infty$ to $+\infty$ and the probability of being at a particular location is described by a normal distribution; along other dimensions, our knowledge is vacuous, i.e., we believe the location of the true value is somewhere from $-\infty$ to $+\infty$ but the associated probability is unknown.

An LBF can represent both logical and probabilistic knowledge for three types of variables: deterministic such as an observable or controllable, random whose distribution is normal, and vacuous on which no knowledge bears. Logical knowledge is represented by linear equations, or geometrically, a certainty hyperplane. Probabilistic knowledge is represented by a normal distribution across all parallel focal elements. We may use an audit problem to illustrate the three types of variables as follows. Suppose we want to audit the ending balance of accounts receivable $(E)$. As we saw earlier, $E$ is equal to the beginning balance $(B)$ plus the sales $(S)$ for the period minus the cash receipts $(C)$ on the sales plus a residual $(R)$ that represents insignificant sales returns and cash discounts. Thus, we can represent the logical relation as a linear equation:

$$
E=B+S-C+R \text {. }
$$

Furthermore, if the auditor believes $E$ and $B$ are 100 on the average with a standard deviation 5 thousand dollars and the covariance 15, we can represent the belief as a multivariate normal distribution. If historical data indicate that the residual $R$ is zero on the average with a standard deviation of 0.5 thousand dollars, we can summarize the historical data by normal distribution $R \sim$ $N\left(0,0.5^{2}\right)$. If there is a direct observation on cash receipts, we can represent the evidence as an equation say, $C=50$ (thousand dollars). If the auditor knows nothing about the beginning balance of accounts receivable, we can represent his or her ignorance by a vacuous LBF. Finally, if historical data suggests that, given cash receipts $C$, the sales $S$ is on the average $8 C+4$ and has a standard deviation 4 thousand dollars, we can represent the knowledge as a linear regression model $S \sim \mathrm{N}(4+8 C, 16)$.

Dempster (1990b) claims that an LBF in its general form is the combination of its degenerate components such as a linear equation, a vacuous belief function, etc. Therefore, he pro- 
Srivastava, Rajendra. (2003) Applications of Belief Functions in Business Decisions: A Review. Information Systems Frontiers, 5 (4), 359-378. Publisher's Official Version: <http://www.som.buffalo.edu/isinterface/ISFrontiers/>.

Open Access Version: <http://kuscholarworks.ku.edu>.

poses representing an LBF indirectly by representing each of its degenerate components as a moment matrix. However, due to the many unproved claims, Dempster (1990b) was never fully understood (see Shafer 1992). Based on the geometrical description by Dempster (1990b), Shafer (1992) and Liu (1996a) propose two mathematical representations of an LBF: a widesense inner product and a linear functional in the variable space, and as their duals over a hyperplane in the frame of discernment. Monney (2002a) proposes a still another structure called Gaussian hints. By relating sweeping operations to multivariate statistics, Liu (1999) further elaborates on Dempster (1990b) and clarifies the moment matrix representation. In this approach, to encode a piece of evidence using an LBF, the key is to represent the mean and covariance, if exist, of variables into a moment matrix. For example, we can use the matrices $M(R)$ and $M(C)$ to represent distribution $R \sim N(0,0.5)$ and direct observation $C=50$ respectively as follows by noting that the variance of $C$ is zero:

$$
M(R)=\left(\begin{array}{c}
0 \\
0.25
\end{array}\right), M(C)=\left(\begin{array}{c}
50 \\
0
\end{array}\right) .
$$

On the other hand, if one is ignorant about a variable, its mean and variance do not exist. Then we need to represent the evidence by a swept matrix. For a one-variable matrix like $M(R)$, a sweeping involves a negative inverse on the variance element and a multiplication of the inverse with the mean element. For example, the sweeping of $M(R)$ is performed as follows:

$$
M(\vec{R})=\left(\begin{array}{c}
0 \times 0.25^{-1} \\
-0.25^{-1}
\end{array}\right)=\left(\begin{array}{c}
0 \\
-4
\end{array}\right) .
$$

Of course, $M(C)$ cannot be swept because the variance is zero. However, we can temporarily imagine the variance as a small number $\varepsilon$ in order to do the sweeping. Eventually, we can let $\varepsilon \rightarrow$ 0 after it is combined with other LBFs. Therefore, $M(C)$ can be swept as follows:

$$
M(\vec{C})=\left(\begin{array}{c}
50 \varepsilon^{-1} \\
-\varepsilon^{-1}
\end{array}\right) .
$$

With the notion of sweeping, a vacuous belief function is represented as a swept matrix with all elements being set zero. For example, if the auditor is completely ignorant about $B$, we can represent the evidence as follows:

$$
M(\vec{B})=\left(\begin{array}{l}
0 \\
0
\end{array}\right)
$$


Srivastava, Rajendra. (2003) Applications of Belief Functions in Business Decisions: A Review. Information Systems Frontiers, 5 (4), 359-378. Publisher's Official Version: <http://www.som.buffalo.edu/isinterface/ISFrontiers/>.

Open Access Version: <http://kuscholarworks.ku.edu>.

Note that variables $B$ and $C$ are semantically at two extremes; $C$ means complete certainty whereas $B$ means complete ignorance. Mathematically, we can see that Equations (8) and (9) are also opposite in the sense that (9) is the result of (8) by letting $\varepsilon \rightarrow \infty$. In other words, we can imagine complete ignorance as the limiting case when the variance increases to $\infty$.

When an LBF involves multiple variables, we will use their means and covariance matrix, if they exist, to form a moment matrix. For example, we can represent the auditor's belief on $E$ and $B$ as the following multivariate moment matrix:

$$
M(E, B)=\left[\begin{array}{cc}
100 & 100 \\
25 & 15 \\
15 & 25
\end{array}\right] .
$$

If both means and covariance matrix do not exit as in the case of complete ignorance, we can represent it by a fully swept moment matrix with all elements being zero like Equation (9). However, in the case we have partial ignorance, i.e., some but not all variables have means, variances, and covariance, we need to represent it as a partially swept matrix ${ }^{3}$.

Note that, for a multivariate moment matrix, a full sweeping is performed through a series of partial sweepings, each of which operates on the variance element of one variable. For example, to fully sweep the moment matrix $M(E, B)$, we can partially sweep it on $B$ first to produce the partially swept matrix $M(E, \vec{B})$ and then partially sweep $M(E, \vec{B})$ on $E$ to produce the fully swept matrix $M(\vec{E}, \vec{B})$ as follows:

$$
M(E, \vec{B})=\left[\begin{array}{cc}
40 & 4 \\
16 & 0.6 \\
0.6 & -1 / 25
\end{array}\right], M(\vec{E}, \vec{B})=\left[\begin{array}{cc}
2.5 & 2.5 \\
-1 / 16 & 3 / 80 \\
3 / 80 & -1 / 16
\end{array}\right]
$$

Also note that a partially swept matrix like $M(E, \vec{B})$ has very rich semantics. According to multivariate statistics, the values 4 and $-1 / 25$ in $M(E, \vec{B})$ contain the sufficient and necessary

\footnotetext{
${ }^{3}$ To do a partial sweeping on an element say, $m_{i j}$, in a multivariate moment matrix, we first replace the element $m_{i j}$ by its negative inverse $\left(-1 / m_{i j}\right)$ and other elements on row $i$ say, $m_{i k}$, where $k \neq j$, or column $j$ say, $m_{k j}$, where $k \neq i$, respectively by $m_{i k} / m_{i j}$ and $m_{k j} / m_{i j}$. Then, for each element not on row $i$ or column $j$ say, $m_{k l}$, where $l \neq j$ and $k \neq i$, we replace it with $m_{k l}-m_{i l} m_{k j} / m_{i j}$.
} 
Srivastava, Rajendra. (2003) Applications of Belief Functions in Business Decisions: A Review. Information Systems Frontiers, 5 (4), 359-378. Publisher's Official Version: <http://www.som.buffalo.edu/isinterface/ISFrontiers/>.

Open Access Version: <http://kuscholarworks.ku.edu>.

information for the marginal distribution of $B$ in the potential form (Lauritzen and Spiegelhalter 1988). The value 40 is the conditional mean of $E$ given $B=0$ whereas 16 is the conditional variance. The value 0.6 is the regression coefficient of $E$ on $B$. Therefore, $M(E, \vec{B})$ represents the conditional probability distribution of $E$ given $B=0$. With these semantics of partially swept matrices, we can represent partial ignorance in which one has knowledge about some variables but is ignorant about others. A linear regression model is such a case. For example, for $S \sim \mathrm{N}(4+$ $8 C, 16$ ), we are completely ignorant about $C$ since it is exogenous. On the other hand, give $C=0$, $S$ is conditionally distributed as $\mathrm{N}(4,16)$. Thus, the regression model $S \sim \mathrm{N}(4+8 C, 16)$ will be represented as a partially swept matrix as follows:

$$
M(S, \vec{C})=\left[\begin{array}{cc}
4 & 0 \\
16 & 8 \\
8 & 0
\end{array}\right]
$$

In the special case when $S=8 C+4$, i.e., $S$ is completely determined given $C$ through a linear equation, the conditional variance of $S$ will be zero in its partial swept matrix:

$$
M(S, \vec{C})=\left[\begin{array}{ll}
4 & 0 \\
0 & 8 \\
8 & 0
\end{array}\right]
$$

Thus, a linear equation is considered as a special case of a linear regression model. Therefore, to represent Equation (5), we use the following partially swept matrix:

$$
M(E, \vec{B}, \vec{S}, \vec{C}, \vec{R})=\left(\begin{array}{ccccc}
0 & 0 & 0 & 0 & 0 \\
0 & 1 & 1 & -1 & 1 \\
1 & 0 & 0 & 0 & 0 \\
1 & 0 & 0 & 0 & 0 \\
-1 & 0 & 0 & 0 & 0 \\
1 & 0 & 0 & 0 & 0
\end{array}\right) .
$$

By adapting Dempster's rule to the continuous case, Liu (1996a) derives a rule of combination in a continuous frame of discernment and proves its equivalence to its geometric description in Dempster (1990b). Liu (1999) further showed that both combination and marginalization of LBFs could be done using the swept matrix representations; the combination corresponds to the sum of fully swept matrices whereas marginalization corresponds to restricting a non-swept matrix into a subset of variables. For example, to combine $M(E, B)$ in Equation (10) with the 
Srivastava, Rajendra. (2003) Applications of Belief Functions in Business Decisions: A Review. Information Systems Frontiers, 5 (4), 359-378. Publisher's Official Version: <http://www.som.buffalo.edu/isinterface/ISFrontiers/>.

Open Access Version: <http://kuscholarworks.ku.edu>.

vacuous $\mathrm{LBF}$ on $B$, we can simply add the corresponding elements in $M(\vec{E}, \vec{B})$ of Equation (11) and $M(\vec{B})$ of Equation (9). Of course, the resulting matrix is the same as $M(\vec{E}, \vec{B})$ since $M(\vec{B})$ $=\mathbf{0}$. This result makes sense because the complete ignorance does not contribute to our knowledge about the variables of interest. For another example, to combine $C=50$ with $S \sim \mathrm{N}(4+8 C$, 16), we first transform $M(S, \vec{C})$ into $M(\vec{S}, \vec{C})$ and then sum it with $M(\vec{C})$ of Equation (8) to obtain the following combination:

$$
M(\vec{S}, \vec{C})=\left[\begin{array}{cc}
1 / 4 & -2+50 \varepsilon^{-1} \\
-1 / 16 & 1 / 2 \\
1 / 2 & -4-\varepsilon^{-1}
\end{array}\right]
$$

Note that, during combinations, we can leave the intermediate matrices like Equation (15) swept. However, when we need to interpret a combination or make an inference using marginalization, we have to do a full reverse sweeping through a series of partial reverse sweepings ${ }^{4}$. For example, by a full reverse sweeping and then letting $\varepsilon \rightarrow 0$, we can transform Equation (15) into:

$$
M(S, C)=\left[\begin{array}{cc}
404 & 50 \\
16 & 0 \\
0 & 0
\end{array}\right] .
$$

Then by marginalizing the combined LBF to variables $S$ and $C$ respectively, we found that $C$ is still 50 with certainty but $S$ is now distributed with mean 404 and variance 16. Furthermore, suppose through testing a sample of sales transactions occurred in the period, we obtain an independent piece of evidence that is encoded as a normal distribution of $S$ say, $S \sim \mathrm{N}(500,25)$. Then we can integrate the new evidence into the above combined belief and obtain the newly updated belief on $S$ as $S \sim \mathrm{N}(441.46,9.76)$.

The notion of LBFs turns out to have a wide range of applications in statistical analysis and business decision-making. In Bayesian statistics, it has been a classic problem that how we

\footnotetext{
${ }^{4}$ To do a partial reverse sweeping on an element say, $m_{i j}$, in a multivariate moment matrix, we first replace the element $m_{i j}$ by its negative inverse $\left(-1 / m_{i j}\right)$ and other elements on row $i$ say, $m_{i k}$, where $k \neq j$, or column $j$ say, $m_{k j}$, where $k \neq i$, respectively by $-{ }^{m_{i k}} / m_{i j}$ and $-{ }^{m_{k j}} / m_{i j}$. Then, for each element not on row $i$ or column $j$ say, $m_{k l}$, where $l$ $\neq j$ and $k \neq i$, we replace it with $m_{k l}-{ }^{m_{i l}} m_{k j} / m_{i j}$.
} 
Srivastava, Rajendra. (2003) Applications of Belief Functions in Business Decisions: A Review. Information Systems Frontiers, 5 (4), 359-378. Publisher's Official Version: <http://www.som.buffalo.edu/isinterface/ISFrontiers/>.

Open Access Version: <http://kuscholarworks.ku.edu>.

can infer a belief distribution of the parameter $\theta$ for a parametric distribution $f(x, \theta)$ given a set of observations. In the framework of DST, Shafer (1982) made an attempt in the case of simple Binomial parametric distributions and demonstrated a tremendous challenge in applying finite belief functions. In contrast, using the theory of LBFs, Dempster (1990b) showed that the problem of statistical inference on linear models is reduced to the one of combining LBFs. His result is identical to Bayesian posterior distribution of the same parameters (see Box and Tiao 1973). Recently, Monney (2002b) derived the same distribution using Fisher's fiducial arguments.

Dempster (1990a, 1990b) also showed how the Kalman filter could be understood in terms of LBFs. As he showed, the recursion involved in the filter can be regarded as a special case of the recursion involved in the computation of LBF marginals in a join tree. The full Kalman filter model results from judging all these component belief functions to be independent, and combining them into a single belief function according to Dempster's rule. Monney (2002a) did similar work in this regard.

Based on the work of Dempster (1990b) in statistical inferences, Liu (2002) attempted to apply LBFs to the combination of linear statistical models. His idea is as follows. The data sets used for inferring individual statistical models can be considered as independent items of evidence. The statistical model inferred from each data set is then represented as an LBF. Then the models from different data sets are combined in a fashion we combine LBFs. Combined predictions or inferences are then made based on the combined model. Obviously, this approach is consistent with the spirit of Dempster's rule of combination. The proposed method generalizes the meta-analysis for integrating independent statistical findings (see Hunter and Schmidt 1990) and the Bayesian method of estimating common regression coefficients (see Box and Tiao 1973). As we see easily, the LBF-based method can combine models of different kinds that may involve different variables. In contrast, the models to be combined in the meta-analysis and the Bayesian method must be the same and the parameters to be estimated must be common.

The notion of LBFs is relatively new. However, there have been some attempts to apply it to real business decisions. In an attempt to shorten the amount of time it takes to perform the modeling, measurement, and analysis of the business processes, which usually must be accomplished before the systems development life cycle takes place, Nelson (2001) describes a method for rapidly producing a performance model of business processes through the use of LBFs. According to him, the performance model can be used to determine the optimal placement of in- 
Srivastava, Rajendra. (2003) Applications of Belief Functions in Business Decisions: A Review. Information Systems Frontiers, 5 (4), 359-378. Publisher's Official Version: <http://www.som.buffalo.edu/isinterface/ISFrontiers/>.

Open Access Version: <http://kuscholarworks.ku.edu>.

formation systems to achieve the maximum benefit for the organization. In another application to information systems management, Liu and Ma (2001) analyzed existing empirical studies by Davis (1989) and others on the two important constructs, perceived ease of use and perceived usefulness, and their relationships to user acceptance and actual usage behavior of emerging information technologies. They synthesized the mixed empirical findings using both the traditional meta-analysis method (Hunter and Schmidt 1990) and the LBF-based approach as described by Liu (2002).

\section{SUMMARY AND CONCLUSION}

In this paper, we walked through the recent applications of Dempster-Shafer theory (DST) of belief functions in auditing and other business decision-making problems. We introduced how a recent addition to the family of DST - the theory of linear belief functions, could provide opportunities for a wide range of real applications.

We showed how DST could better model real-world uncertainties than its competing approach-Bayesian theory of probabilities. From both classic and real-world examples, we learned that the advantage of DST in representing ignorance and partial ignorance over its competing theory is its ability to distinct lack of belief from disbelief and to allow people to withhold their belief from a statement without according that belief to the negation of the statement. From the review of existing empirical evidence, we learned that, descriptively, people tend to make judgments about uncertainties in terms of belief functions.

Following the audit process defined by Arens and Loebbecke (2000), we described three types of audit evidence, namely hierarchical evidence, versatile evidence, and statistical evidence, that have to be collected and assembled to make a judgment whether a financial statement is fairly presented. Hierarchical evidence arises due to SAS 31 that stipulates auditing standards at three hierarchical levels: the financial statement level, the account level, and the objective level. Versatile evidence arises when a piece of information implies two or more belief mass allocations, usually, on several different variables. Statistical evidence is prevalent in auditing because, according to the audit risk model, a planned level of detection risk has to be attained through substantive audit procedures including statistical tests.

We reviewed the applications of DST in auditing around how they handled the three types of evidence. We introduced with care the work of Srivastava and Shafer (1992) on convert- 
Srivastava, Rajendra. (2003) Applications of Belief Functions in Business Decisions: A Review. Information Systems Frontiers, 5 (4), 359-378. Publisher's Official Version: <http://www.som.buffalo.edu/isinterface/ISFrontiers/>.

Open Access Version: <http://kuscholarworks.ku.edu>.

ing audit risks into $\mathrm{m}$-values through their re-interpretation as plausibilities and on attaching the audit risk model to all three levels of an audit problem. We showed how they represented hierarchical evidence using a tree-structured graphical model. We illustrated the Srivastava and Cogger approach to extending marginal belief functions into joint ones and how existing applications have applied it to coping with versatile evidence. We reviewed the applications that convert statistical evidence in variable and attribute sampling to evidence in belief functions. Finally, we looked at an extended framework of audit planning that considered explicitly the risk of fraud due to the inception of SAS 82. We presented an evidential network with hierarchical evidence, which propagates not only through "AND" gates but also "OR” gates.

For the applications in other non-auditing areas, we grouped them into two loose categories: judgment and decision-making under ambiguity, and business model combination. We showed how the proponents of DST looked at the Ellsberg paradox and how empirical evidence was in support of their perspective. Then we briefly reviewed the remaining applications under the theme of combining business models. These applications are in miscellaneous areas including WebTrust, information quality, business mergers and acquisitions, mobile satellite service, and portfolio modeling, etc.

Finally, we reviewed the applications of linear belief functions (LBF) - a new extension to DST, in statistical modeling and information systems management. Since the theory of LBFs is relatively new, we introduced its conception originally envisioned by Dempster (1990b). We elaborated the idea of the matrix representation by Dempster (1990b) and presented an elementary approach to encoding the most common types of evidence using an audit example. We described the rationale of how the notion of LBFs was used in the existing applications.

In this paper, although we reviewed the applications of DST in many business areas, we singled out those in audit decisions and thoroughly examined them at a level of technical details. Our emphasis on audit decisions is partially due to the abundance of such applications. It is also partially due to the fact that the technical challenge in mapping audit evidence also challenges other business applications. By synthesizing the applications in both audit and non-audit decisions, we found that the core of mapping real-world uncertainties lies at encoding hierarchical evidence, versatile evidence, and statistical evidence, into belief functions. The challenge in dealing with hierarchical evidence lies at how we combine items of evidence that are present at different levels of a hierarchy, especially when the items of evidence are connected through logi- 
Srivastava, Rajendra. (2003) Applications of Belief Functions in Business Decisions: A Review. Information Systems Frontiers, 5 (4), 359-378. Publisher's Official Version: <http://www.som.buffalo.edu/isinterface/ISFrontiers/>.

Open Access Version: <http://kuscholarworks.ku.edu>.

cal 'AND' and 'OR' gates. The challenge of handling versatile evidence lies at how to convert marginal belief functions into ones in a joint space while preserving the interdependencies among the relevant variables. The challenge of handling statistical evidence is at how to convert sampling data into belief functions so that they can be combined with subjective opinions.

In addition to the applications in auditing, we also reviewed the conception and applications of LBFs at a level of technical details. Our emphasis here is to demonstrate how this new addition to DST can give impetus to a wider range of applications of DST in business decisions. We showed that, like finite belief functions, the theory of LBFs possesses the usual advantages of the belief function modeling - the representation of ignorance by vacuous belief functions, the resolution of complex representations of uncertainty into components by graphical models, and the combination of independent models by Dempster's rule. As Dempster (1990b) argued, the notion of LBFs generalizes Bayesian inference of posterior distributions while abandoning its most controversial component: improper priors. It extends, unifies, and clarifies Fisher's fiducial method of posterior reasoning while filling the void of a prior distribution in the logical structure with a vacuous belief function. Its join-tree computational architecture (see Liu 1999) extends a parallel concept for probabilistic models (Lauritzen and Spiegelhalter 1988), but eliminates the requirement of conceiving and imposing directional structure on the graph whereby earlier components of uncertain knowledge are judged asymmetrically prior to later components that are described as conditional likelihood. The specification of graphical belief function models is based on symmetric evidential independence assumptions that are simpler and more directly susceptible to empirical checking than are typical Bayesian conditional probability assumptions that are assumed to hold given arbitrary choices of often long lists of unknown parameter values specifying families of both distributions and conditions. Also, the conception of an LBF treats all the components of a statistical model such as observations, model assumptions, and subjective beliefs, not as separate concepts, but as manifestations of a single concept. It allows people to concentrate modeling efforts on recognizing and incorporating independent components of real information that can be combined into a graphical model.

Linear equations that link random variables are prevalent in many scientific and applied fields. The conception of an LBF allows one to capture them directly as an LBF. This property of an LBF alone can generate tremendous opportunities for its applications in the fields. For example, as Shenoy and Shenoy (2002) showed, the return on an individual security is linearly de- 
Srivastava, Rajendra. (2003) Applications of Belief Functions in Business Decisions: A Review. Information Systems Frontiers, 5 (4), 359-378. Publisher's Official Version: <http://www.som.buffalo.edu/isinterface/ISFrontiers/>.

Open Access Version: <http://kuscholarworks.ku.edu>.

termined by factors such as stock market, gold price, firm-specific effects, and a residue. Furthermore, the portfolio return is the weighted average of the returns on individual securities. Both relationships are linear equations and therefore can be captured as LBFs. We can encode expert opinions and historical data on the factors that affect individual securities as additional LBFs. Then the whole evidential reasoning problem of portfolio prediction described in Shenoy and Shenoy (2002) becomes the one of combining those LBFs.

\section{REFERENCES}

Akresh AD, Loebbecke JK, Scott WR. Audit approaches and techniques. In: Abdel-khalik AR, Solomon Ira, editors. Research Opportunities in Auditing: The Second Decade. Sarasota, FL: AAA; 1988. pp 13-55.

American Institute of Certified Public Accountants. Statement on Auditing Standards, No, 31: Evidential Matter, New York: AICPA; 1980.

American Institute of Certified Public Accountants. Statement on Auditing Standards, No, 47: Audit Risk and Materiality in Conducting an Audit. New York: AICPA; 1983.

American Institute of Certified Public Accountants. Statement on Auditing Standards, No. 53: The Auditor's Responsibility to Detect and Report Errors and Irregularities. New York: AICPA; 1988a.

American Institute of Certified Public Accountants. Statement on Auditing Standards, No. 55: Consideration of the Internal Control Structure in a Financial Statement Audit. New York: AICPA; 1988b.

American Institute of Certified Public Accountants. Statement on Auditing Standards, No. 82: Consideration of Fraud in a Financial Statement Audit. New York: AICPA; 1997a.

American Institute of Certified Public Accountants. AICPA/CICA WebTrust Principles and Criteria for Businessto-Consumer Electronic Commerce. http://www.aicpa.org/webtrust/princrit/htm; 1997b.

American Institute of Certified Public Accountants. Report of the Special Committee on Assurance Services. http://www.aicpa.org; 1997c.

Anrig B, Haenni R, Kohlas, J, Lehmann N. Assumption-based Modeling using ABEL. In: Gabbay D, Kruse R, Nonnengart A, Ohlbach HJ, editors. First International Joint Conference on Qualitative and Quantitative Practical Reasoning; ECSQARU--FAPR'97. Lecture Notes in Artificial Intelligence. Springer-Verlag; 1997.

Arens AA, Loebbecke JK. Auditing: An Integrated Approach. Englewood Cliffs, NJ: Prentice-Hall; 2000.

Boritz JE. Appropriate and inappropriate approaches to combining evidence in an assertion-based auditing framework. Working Paper. School of Accountancy, University of Waterloo, Canada; 1990.

Boritz JE, Jensen RE. An hierarchical, assertion-oriented approach to planning audit evidence-gathering procedures. Presented at the Symposium on Audit Judgment and Evidence Evaluation, University of Southern California; 1985.

Bovee M, Srivastava RP, Mak B. A Conceptual Framework and Belief-Function Approach to Assessing Overall Information Quality. Presented at the Information Quality Conference at MIT. Boston; November 2-4, 2002.

Box GEP, Tiao GC. Bayesian Inference in Statistical Analysis. Reading, MA:Addison-Wesley; 1973.

Curley SP, Golden JI. Using belief functions to represent degrees of belief. Organization Behavior and Human Decision Processes; 1994. pp 271 - 303.

Cushing BE, Loebbecke JK. 1983. Analytical approaches to audit risk: A survey and analysis. Auditing: A Journal of Practice and Theory 3, 1983, Fall, pp. 23-41. 
Srivastava, Rajendra. (2003) Applications of Belief Functions in Business Decisions: A Review. Information Systems Frontiers, 5 (4), 359-378. Publisher's Official Version: <http://www.som.buffalo.edu/isinterface/ISFrontiers/>.

Open Access Version: <http://kuscholarworks.ku.edu>.

Davis FD. Perceived usefulness, perceived ease of use, and user acceptance of information technology. MIS Quarterly; 1989. 13(3):319-339.

Dempster AP. New methods for reasoning towards posterior distributions based on sample data. Annals of Mathematical Statistics; 1966. 37:355-374.

Dempster AP. Upper and lower probabilities induced by a multivalued mapping. Annals of Mathematical Statistics; 1967. 38:325-339.

Dempster AP. Elements of Continuous Multivariate Analysis, Reading, MA:Addison-Wesley; 1969.

Dempster AP. Construction and local computation aspects of network belief functions. In: Oliver R.M, Smith JQ, editors. Influence Diagrams, Belief Nets, and Decision Analysis. Chichester: John Wiley and Sons; 1990a.

Dempster AP. Normal belief functions and the Kalmam filter. Research Report. Department of Statistics, Harvard University, Cambridge, MA; $1990 \mathrm{~b}$.

Dempster AP. Belief functions in the 21st Century: A Statistical Perspective. Presented to INFORMS Annual Meeting 2001. Miami Beach, FL; 2001.

Dubois D, Prade H. The Principles of Minimum Specificity as a Basis for Evidential Reasoning. Lecture Notes in Computer Science. In: Goos, G, Hartmanis, J, editors. Springer-Verlag; 1986.

Dubois D, Prade H. The Principles of Minimum Specificity as a Basis for Evidential Reasoning. In: Bouchon B, Yager RR, editors. Uncertainty in Knowledge-Based Systems. LNCS. Springer-Verlag; 1987. 286:74-84.

Dubois D, Prade H. Evidence, Knowledge, and Belief Functions. Internal Journal of Approximate Reasoning. 1992. 6:295-319.

Dubois D, Prade H. Focusing versus Updating in Belief Function Theory. In: Yager RR, Fedrizzi M, Kacprzyk, editors. Advances in the Demster-Shafer Theory of Evidence. New York, NY: John Wiley and Sons; 1994. pp 71-95.

Dusenbury R, Reimers J, Wheeler S. An Empirical Study of Belief-Based and Probability-Based Specifications of Audit Risk. Auditing: A Journal of Practice and Theory; Fall, 1996. Vol. 15(2): 12-28.

Dutta SK, Srivastava, RP. Belief Revision in Auditing: A Theoretical Investigation. Proceedings of the 21st Annual Western Decision Science Meeting. Reno Nevada; March 1992: 24-27.

Dutta SK, Harrison K, Srivastava RP. The Audit Risk Model Under the Risk of Fraud. In: Siegel P, Omer K, Korvin A, Zebda A. Applications of Fuzzy Sets \& The Theory of Evidence to Accounting II. Jai Press Inc; 1998. 7:221-244.

Dutta SK, Srivastava RP. Belief Revisions In Auditing: A Theoretical Investigation. In: Ribeiro R, Yager RR, Zimmermann HJ, Kacprzyk J, editors. Soft Computing in Financial Engineering. Physica-Verlag, Heidelberg, Springer-Verlag Company; 1999. pp. 484-498.

Ellsberg D. Risk, Ambiguity, and the Savage Axioms. Quarterly Journal of Economics; 1961. 75:643-669.

Engemann KJ, Miller HE, Yager RR. Decision Making with Belief Structures: An Application in Risk Management. International Journal of Uncertainty, Fuzziness, and Knowledge Based Systems. 1996. 4:1-25.

Fishburn PC. A Variational Model of Preference under Uncertainty. Technical Report. AT\&T Bell Lab. NJ; 1993.

Gillett PR. A Comparative Study of Audit Evidence and Audit Planning Models using Uncertain Reasoning. Ph.D. Dissertation. School of Business, University of Kansas; 1996.

Gillett PR. Monetary unit sampling: a belief-function implementation for audit and accounting applications. International Journal of Approximate Reasoning; 2000. 25:43-70.

Gillett PR, Srivastava RP. Attribute Sampling: A Belief-Function Approach to Statistical Audit Evidence. Auditing: A Journal of Practice and Theory, Spring 2000. 19(1):145-155.

Graham L. Audit Risk - Part I. The CPA Journal. August 1985a. pp 15-21.

Graham L. Audit Risk - Part II. The CPA Journal. September1985b. pp 34-40. 
Srivastava, Rajendra. (2003) Applications of Belief Functions in Business Decisions: A Review. Information Systems Frontiers, 5 (4), 359-378. Publisher's Official Version: <http://www.som.buffalo.edu/isinterface/ISFrontiers/>.

Open Access Version: <http://kuscholarworks.ku.edu>.

Graham L. Audit Risk - Part III. The CPA Journal. October 1985c. pp 36-43.

Graham L. Audit Risk - Part IV. The CPA Journal. November 1985d. pp 38-44.

Graham L. Audit Risk - Part V. The CPA Journal. December 1985e. pp 26-33.

Guy D, Carmichael D, Ray O. Whitington. Audit Sampling: An Introduction, 5th Edition. John Wiley \& Sons, Inc; 2002.

Hacking I. The Emergence of Probability. New York: Cambridge University Press; 1975.

Harrison K. Evaluation and Aggregation of Audit Evidence under Uncertainty: An Empirical Study of Belief Functions. Ph.D. Dissertation. School of Business, University of Kansas; 1999.

Harrison K, Srivastava RP, Plumlee RD. Auditors' Evaluations of Uncertain Audit Evidence: Belief Functions versus Probabilities. In: Srivastava RP, Mock T, editors. Belief Functions in Business Decisions. Physica-Verlag, Heidelberg, Springer-Verlag Company, 2002: 161-183.

Hogarth RM, Einhorn HJ. Venture Theory: A Model of Decision Weights. Management Science; 1990. 36:780803.

Hogarth RM, Einhorn HJ. Order Effects in Belief Updating: The Belief Adjustment Model. Cognitive Psychology; January1992. pp 1-55.

Hunter JE, Schmidt FL. Methods of Meta-Analysis: Correcting Error and Bias in Research Findings. Sage. Newbury Park, CA; 1990.

Jaffray JY. Linear utility theory for belief functions. Operations Research Letters 8; 1989. pp 107-112.

Jaffray JY. Dynamic Decision Making with Belief Functions. In: Yager RR, Fedrizzi M, Kacprzyk, editors. Advances in the Demster-Shafer Theory of Evidence. New York, NY: John Wiley and Sons; 1994.

Jung, MKP, Fink HE. The Effectiveness and Efficiency of Belief Based Audit Procedures. Belief Functions in Business Decisions. In: Srivastava R, Mock T, editors. Physica-Verlag, Heidelberg, Springer-Verlag Company; 2002: 139-160.

Kinney Jr. WR. Discussant's response to an analysis of the audit framework focusing on inherent risk and the role of statistical sampling in compliance testing. Proceedings of the 1984 Touche Ross/University of Kansas Symposium on Auditing Problems. Lawrence, KS: School of Business, University of Kansas; 1984. pp 126-32.

Kinney Jr. WR. Achieved audit risk and the audit outcome space. Auditing: A Journal of Practice and Theory 8 (Supplement); 1989. pp. 67-97.

Krishnamoorthy G, Mock TJ, Washington MT. A Comparative Evaluation of Belief Revision Models. Auditing. Auditing: A Journal of Practice \& Theory; Fall, 1999. pp 104-127.

Lauritzen SL, Spiegelhalter DJ. Local computation with probabilities on graphical structures and their application to expert systems (with discussion). Journal of the Royal Statistical Society Series B; 1988. 50:157-224.

Lea RB, Adams SJ, Boykin RF. Modeling of the Audit Risk Assessment Process at the Assertion Level Within an Account Balance. Auditing: A Journal of Practice and Theory, Supplement; 1992. 11:152-179.

Leslie DA. An analysis of the audit framework focusing on inherent risk and the role of statistical sampling in compliance testing. Proceedings of the 1984 Touche Ross/University of Kansas Symposium on Auditing Problems. Lawrence, KS: School of Business, University of Kansas; 1984. pp. 89-125.

Leslie DA, Aldersley SJ, Cockburn DJ, Reiter CJ. An Assertion Based Approach to Auditing. Proceedings of the 1986 Touche Ross/University of Kansas Symposium on Auditing Problems; May 1986. pp. 31-67.

Lien D. Futures Hedging under Prospect Utility and Knightian Uncertainty. In Srivastava RP, Mock T, editors. Belief Functions in Business Decisions. Physica-Verlag, Heidelberg, Springer-Verlag Company; 2002: 333-345.

Liu L. A theory of coarse utility and its applications to portfolio analysis. Ph.D. Dissertation. School of Business, University of Kansas, Lawrence, Kansas; 1995a. 
Srivastava, Rajendra. (2003) Applications of Belief Functions in Business Decisions: A Review. Information Systems Frontiers, 5 (4), 359-378. Publisher's Official Version: <http://www.som.buffalo.edu/isinterface/ISFrontiers/>.

Open Access Version: <http://kuscholarworks.ku.edu>.

Liu L, Shenoy PP. A theory of coarse utility. Journal of Risk and Uncertainty; 1995b. (11) 17-49.

Liu L. A theory of Gaussian belief functions. International Journal of Approximate Reasoning; 1996a. 14:95-126.

Liu, L. Propagation of Gaussian belief functions. In: Fisher D, Lenz H, editors. Learning from Data: Artificial Intelligence and Statistics V. New York: Springer-Verlag; 1996b. pp 79-88.

Liu L. Local Computation of Gaussian Belief Functions. International Journal of Approximate Reasoning; 1999. 22:217-248.

Liu, L. Model Combination Using Gaussian Belief Functions. Presented at INFORMS Annual Meeting, Miami, FL; November, 2001.

Liu L, Ma. Q. A Meta-Analysis on Technical Acceptance Models Using Gaussian Belief Functions. Presented at INFORMS Annual Meeting, Miami, FL; November, 2001.

Liu L, Shenoy PP. Representing Asymmetric Decision Problems Using Coarse Valuations. Working Paper. University of Akron, Akron, $\mathrm{OH} 44325-4801 ; 2002$.

McBurney P, Parsons S. Belief Functions and Scenario Planning. In Srivastava RP, Mock T, editors. Belief Functions in Business Decisions. Physica-Verlag, Heidelberg, Springer-Verlag Company; 2002: 281-315.

Mock TJ, Turner JL. An Archival Study of Audit Fraud Risk Assessments Made Under SAS No.82. Working Paper. University of Southern California; 2002.

Mock TJ, Wright A, Srivastava R. Audit Program Planning Using a Belief Function Framework. University of Kansas Audit Research Symposium; 1998.

Monney PA. Assumption-Based Reasoning with Functional Models. Habilitation Thesis, School of Economics and Social Sciences, University of Fribourg, Switzerland. To appear as a volume in the Springer-Verlag Series Contributions to Statistics. 2002.

Monney, PA. Analyzing Linear Regression Models with Hints and Dempter-Shafer Theory. Presented at INFORMS Annual Meeting, Miami, FL; November, 2001. To appear in International Journal of Intelligent Systems.

Monroe G, Ng J. The Descriptive Ability of Models of Audit Risk. In: Srivastava R, Mock T, editors. Belief Functions in Business Decisions. Physica-Verlag, Heidelberg, Springer-Verlag Company; 2002: 113-138.

Nelson J. Rapid Process Performance Modeling with Gaussian Belief Functions. Presented at INFORMS Annual Meeting, Miami, FL; November, 2001.

Saffiotti A, Umkehrer E. Pulcinella: A General Tool for Propagating Uncertainty in Valuation Networks. Proceedings of the Seventh National Conference on Artificial Intelligence. University of California at Los Angeles; 1991. pp 323-331.

Savage LJ. The Foundations of Statistics. New York: Wiley; 1954.

Sennetti JT. Toward a More Consistent Model for Audit Risk. Auditing: A Journal of Practice and Theory; Spring, 1990. pp. 103-112.

Shafer G. A Mathematical Theory of Evidence. Princeton University Press; 1976.

Shafer G. Belief Founctions and Parametric Models. Journal of the Royal Statistical Society B; 1982. 44(3):322352.

Shafer G. A note on Demster's Gaussian belief functions. Technical report. School of Business, University of Kansas. Lawrence, KS; 1992.

Shafer G, Shenoy PP, Srivastava RP. AUDITOR'S ASSISTANT: A Knowledge Engineering Tool For Audit Decisions. Proceedings of the 1988 Touche Ross University of Kansas Symposium on Auditing Problems; May 1988. pp 61-79.

Shafer G, Srivastava RP. The Bayesian And Belief-Function Formalisms: A General Perspective for Auditing. Auditing: A Journal of Practice and Theory, Supplement; 1990. pp110-148. 
Srivastava, Rajendra. (2003) Applications of Belief Functions in Business Decisions: A Review. Information Systems Frontiers, 5 (4), 359-378. Publisher's Official Version: <http://www.som.buffalo.edu/isinterface/ISFrontiers/>.

Open Access Version: <http://kuscholarworks.ku.edu>.

Shenoy PP, Shafer G. Propagating Belief Functions using Local Computations. IEEE Expert; 1986. 1(3): 43-52.

Shenoy PP, Shafer G. Axioms for Probability and Belief-Function Propagation. Uncertainty in Artificial Intelligence, In: Shachter RD, Levitt TS, Lemmer JF, Kanal LN, editors. North-Holland; 1990. 4:169-198.

Shenoy C, Shenoy PP. Modeling Financial Portfolios Using Belief Functions. In: Srivastava R, Mock T, editors. Belief Functions in Business Decisions. Physica-Verlag, Heidelberg, Springer-Verlag Company; 2002: 316332.

Smets P. The Combination of Evidence in the Transferable Belief Model. IEEE Transactions on Pattern Analysis and Machine Intelligence; May 1990a. 12(5).

Smets P. Constructing the Pignistic Probability Function in a Context of Uncertainty. Uncertainty in Artificial Intelligence 5. In: Henrion M, Shachter RD, Kanal LN, Lemmer, JF, editors. North-Holland: Elsevier Science Publishers B.V.; 1990b.

Smets P. The Transferable Belief Model For Quantified Belief Representation. Quantified Representation for Uncertainty and Imprecision. In: Smets P., editors. Kluwer Academic Publishers; 1998. Vol. 1.

Srivastava RP. Belief Functions and Audit Decisions, Auditors Report; Fall 1993. 17(1): 8-12.

Srivastava RP. A General Scheme for Aggregating Evidence in Auditing: Propagation of Beliefs in Networks. In: Miklos VA, editor. Artificial Intelligence in Accounting and Auditing. Markus Wiener Publishers, Princeton; 1995a. 3:55-99.

Srivastava RP. The Belief-Function Approach to Aggregating Audit Evidence. International Journal of Intelligent Systems; 1995b. pp. 329-356.

Srivastava RP. Value Judgments using Belief Functions. Research in Accounting Ethics; 1996. 2:109-130.

Srivastava RP. Decision Making Under Ambiguity: A Belief-Function Perspective. Archives of Control Sciences; 1997a. Vol. 6 (XLII), No. 1-2, pp. 5-27.

Srivastava RP. Audit Decisions Using Belief Functions: A Review, Control and Cybernetics; 1997b. 26(2):135160.

Srivastava RP. Integrating Statistical and Non-Statistical Evidence Using Belief Functions. In: Kent A, Williams JG, Hall CM, editors. Encyclopedia of Computer Science and Technology. New York:Marcel Dekker, Inc.; 1997c. Supplement 22, 37:157-174.

Srivastava RP, Datta D. Evaluating Mergers and Acquisitions: A Belief Function Approach. In: Srivastava RP, Mock T, edited. Belief Functions in Business Decisions. Physica-Verlag, Heidelberg, Springer-Verlag Company; 2002: 222-251.

Srivastava RP, Dutta SK, Johns R. An Expert System Approach to Audit Planning and Evaluation in the BeliefFunction Framework. International Journal of Intelligent Systems in Accounting, Finance and Management; 1996. 5(3):165-183.

Srivastava RP, Lu H. Structural Analysis of Audit Evidence using Belief Functions. Fuzzy Sets and Systems; 2002.

Srivastava RP, Mock TJ. Evidential Reasoning for WebTrust Assurance Services. Journal of Management Information Systems; Winter, 1999-2000. 10(3):11-32.

Srivastava RP, Mock TJ. Belief Functions in Accounting Behavioral Research. Advances in Accounting Behavioral Research, Stamford, Connecticut:Jai Press Inc.; 2000. 3:225-242.

Srivastava RP, Mock TJ. Belief Functions in Business Decisions. Physica-Verlag, Heidelberg, Springer-Verlag Company; 2002.

Srivastava RP, Shafer G. Belief-Function Formulas for Audit Risk. The Accounting Review; April 1992. pp 249283.

Srivastava RP, Shafer G. Integrating Statistical and Non-Statistical Audit Evidence Using Belief Functions: A Case of Variable Sampling. International Journal of Intelligent Systems; 1994. pp. 519-539. 
Srivastava, Rajendra. (2003) Applications of Belief Functions in Business Decisions: A Review. Information Systems Frontiers, 5 (4), 359-378. Publisher's Official Version: <http://www.som.buffalo.edu/isinterface/ISFrontiers/>.

Open Access Version: <http://kuscholarworks.ku.edu>.

Srivastava RP, Shenoy PP, Shafer G. Propagating Beliefs in an 'AND' Tree. International Journal of Intelligent Systems; 1995. 10:647-664.

Strat TM. Decision analysis using belief functions, International Journal of Approximate Reasoning 4; 1990. pp 391-417. 24

Strat TM. Decision Analysis using Belief Functions. In: Yager RR, Fedrizzi M, Kacprzyk, editors. Advances in the Demster-Shafer Theory of Evidence. New York, NY: John Wiley and Sons; 1994.

Sun L, Srivastava RP, Mock T. Belief Function Approach to Evidential Reasoning for WebTrust Assurance Services: A Case Study. Presented at the INFORMS Conference in Miami; November 2001. pp 4-8.

Turner JL. Order and Level Effects of Negative Evidence Regarding Internal Accounting Controls: An Examination of Alternative Models of Audit Judgment. Ph. D. Dissertation. Texas A \& M University; 1994.

Turner J, Mock TJ, Srivastava RP. A Conceptual Framework for Audit Planning \& Evaluation Given the Potential for Fraud. Working Paper, University of Kansas; 2002.

Xu H. A Decision Calculus for Belief Functions in Valuation-Based Systems. In: Dubois D, Wellman MP, D'Ambrosio B, Smets Ph, editors. Proc. 8th Uncertainty in Artificial Intelligence. San Mateo, Ca.:Morgan Kaufmann; 1992. pp 352-359.

Yager RR. Decision Making under Dempster-Shafer Uncertainties, Iona College Machine Intelligence Institute Tech. Report MII-915; 1989. 